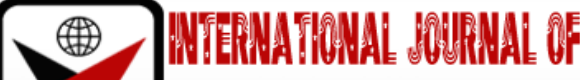

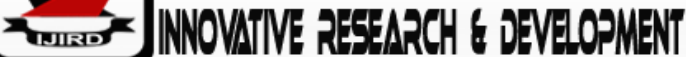

ISSN 2278-0211 (Online)

\section{Human Capital Focus and Organisational Performance in Kenya}

\author{
Justus Bundi Miriti \\ Doctoral Candidate, Department of Business Administration, \\ Kenya Methodist University, Kenya \\ Thomas Anyanje Senaji \\ Professor, Department of Academics and Research, \\ East African University, Kenya \\ Nancy Gacheri Rintari \\ Senior Lecturer, Department of Business Administration, \\ Kenya Methodist University, Kenya
}

\begin{abstract}
:
Leadership and governance determines success of organisations of all types and their sustainability hence the interest in what effective leadership is and how it relates with effectiveness of organisations. Drawing from strategic leadership model and transformational leadership theory we examined the relationship between human capital focus and organisational effectiveness in a Kenyan context using cross-sectional survey of 133 managers in savings and credit cooperative societies. We found that leaders had a moderate human capital focus ( $M=3.91, S D=.69)$, performance was moderate $(M=3.80, S D=.79)$ and that three leader human capital focus behaviors reported by followers: 'considers my feelings before acting' $(r=.324, p<.001)$, 'sees that my interests are given due consideration' $(r=.216, p=0.012)$ ', and 'encourages $m e$ to be the best that I can be' $(r=.508, p<.001)$, were positively and significantly related with organizational effectiveness while 'behaves in a manner which is thoughtful of my personal needs' $(r=.044, p=.616>$ .05) was not significantly related with organisational effectiveness. In particular, inspiring the followers including encouraging them to be the best that they can be had the strongest relationship with performance. Overall, human capital focus was moderately correlated with organisational effectiveness ( $r=.359, p<.001)$. In addition, consideration of feelings and encouragement of followers significantly influenced probability of satisfactory performance by increasing the odds of satisfactory performance by about two times $(\exp (B)=1.904)$ and more than threefold $(\exp (B)=3.301)$ respectively. However, 'thoughtfulness' and 'attention of follower interests' did not significantly influence the odds for organizational effectiveness (satisfactory performance) (thoughtfulness: Wald $=1.781, t=.182$, exp $(B)=.641$; attention to follower interests: Wald $=1.409, t=.235$, exp $(B)=.745)$. These findings suggest that leaders should improve human capital focused behaviors in order to improve their performance because the practice of these behaviours and performance were only moderately satisfactory. Further, there is need to conduct further study to determine why leaders' thoughtfulness of followers' personal needs appeared not to significantly relate with performance.
\end{abstract}

Keywords: Strategic leadership, human capital, performance, SACCOs, Kenya

\section{Introduction}

Strategic leadership (SL) has become important for organizations due to heightened competition and an ever discerning customer. It ensures that a balance between internal organization focus and the demands of the external environment; and between the need for exploitation of available opportunities while exploring other opportunities as they unfold.

According to Davies and Davies (2014, p. 30), 'strategic leaders have the organizational ability to be strategically orientated; translate strategy into action; align people and organizations; determine effective strategic intervention points; and develop strategic competencies'. They also 'display a dissatisfaction or restlessness with the present; absorptive capacity; adaptive capacity; and wisdom), (p. 30). Further, Ireland and Hitt (2005) conceptualize strategic leadership as a set of unique capabilities of anticipating, envisioning, maintaining flexibility, thinking in a strategic way, and empowering employees to generate innovative ideas that lead to high performance. Drawing from this (Ireland \& Hill, 199) conceptualization, specifically 'empowering employees', the notion of human capital focus comes to the fore. This focus is also grounded by the transformational leadership theory's variables - consideration and inspiration

The essence of any organisation is to achieve the goal for which it was established as observed through performance measures. The definition of organizational performance is an open question with few studies using consistent definitions and measures (Kirby, 2005). Performance is very common in management research although its 
structure and definition are rarely explicitly justified; instead, its appropriateness, in no matter what form, is unquestionably assumed (Richard, 2009).

In a highly competitive environment, organizations should provide quality products and services to their clients and satisfy the needs of their stakeholders. SACCOs are not an exception; they need to provide financial services to their customers when demanded otherwise the customers will seek alternative financial services. This calls for effective leadership which would guarantee satisfactory performance. The performance of SACCOs can be discerned from capital adequacy and liquidity as well as from organisational effectiveness measures such as innovation, coordination of activities and adaptability to the rapidly changing environment. In this study, the latter perspective was adopted. SACCOs are an important context for this study because they contribute financial inclusion which is crucial for the attainment of development goals.

Consequently, assessment of organization performance is a fundamental component of the management process in any type of corporation. This draws attention to the need to examine the antecedents of performance. In particular, leadership and governance determines success of organisations of all types and their sustainability hence the interest in what effective leadership is and how it relates with effectiveness of organisations.

Drawing from strategic leadership model and transformational leadership theory we examined the relationship between human capital focus and organisational effectiveness in a Kenyan context using cross-sectional survey of 133 managers in savings and credit cooperative societies.

\section{Theory and Hypothesis}

According to Ogola and Senaji (2018, p.12) 'Transformational leadership theory is based on the concept that certain leader behaviors transform followers' values, needs, preferences, and aspirations, and motivate them, to perform above and beyond the call of duty'. Transformational leadership influences change in individuals and collective systems in communities and organizations (Ogola, 2019). It creates and builds valuable and positive transformation on the followers with the purpose of developing followers into similar leaders (Burns \&Avolio, 2006). Additionally, the transformational leadership empowers followers to display exceptionally high outcomes (Burns, 1978) which results in improved organizational performance. The leader recognizes the required change through inspiration, and executes the change with the commitment of the team members (Yang, 2012). This theory implies the importance of leader's behaviours that are characterised by: considering feelings of followers before acting ('consideration'), behaving in a manner which is thoughtful of followers personal needs ('thoughtfulness'), seeing to it that interests of followers are given due consideration ('attention to follower interests'), and encouraging followers to be the best that they can be ('encouragement').

A company's or any other organisation's performance is a complex phenomenon requiring more than a single criterion to measure it (Zhu \&Akthar, 2014). For example, both financial and nonfinancial measures of performance should be considered when assessing this phenomenon. Kaplan and Norton, (1992) presented the balanced scorecard (BSC) which proposes a holistic view of the organization by integrating four perspectives of performance: financial, customer, internal business processes, and innovation and growth. The financial perspective (shareholder value) is the final aim of the business, even if they recognize the need to balance with the other three dimensions.

Thus, drawing from the transformational leadership theory and adopting the human capital focus perspective; and noting that high outcomes arising from transformational leadership may be related with improved organisational performance (see e.g., Burns, 1978; Ogola, 2019), we posited as follows:

- $\mathrm{H}_{01}$ Consideration has no significant influence on organisational performance

- $\mathrm{H}_{02}$ Thoughtfulness has no significant relationship with organisational performance

- $\mathrm{H}_{03}$ Attention to follower interests has no significant relationship with organisational performance

- $\mathrm{H}_{04}$ Encouragement does not significantly influence organisational performance

These hypotheses were tested using data from SACCOs in Kenya.

\section{Methodology}

The aim of this study was to test hypothesis by objectively colleting a large amount of quantitative data, analyzing it and making inferences (see e.g. Easterby-Smith, Thorpe \& Lowe, 1991). Consistent a positivist paradigm a descriptive cross sectional survey of 133 management level respondents was conducted using structured questionnaires to collect quantitative data. The validity and reliability of questionnaire was assessed before use and all Cronbach alpha statistics where above 0.7.Human capital was operationalised using four variables: Consideration ('My supervisor considers my feelings before acting'),Thoughtfulness ('My supervisor behaves in a manner which is thoughtful of my personal needs'), Attention to follower interests ('My supervisor sees that my interests are given due consideration'), and Encouragement ('My supervisor encourages me to be the best that I can be')

Gauging from the Cronbach (1951) alpha reliability test statistic items were internally consistent as measures of human capital focus construct. Further, organisational performance was measured using three organisational effectiveness measures namely 'My organization has introduced innovations of new products/services' (innovation), 'My organization has improved its coordination of the development efforts of different units' (coordination), and 'My organisation is adapting quickly to unanticipated changes' (adaptability)

Upon obtaining contacts of the respondent organisations from the SACCO Societies Regulatory Authority (SASRA) website questionnaire was self-administered and distributed by both drop-and-pick-later method and through google forms online questionnaires. The respondents were at management levels and were either a manager, the CEO or their representatives who were senior managers; one each from all the 133 SACCOs that responded to the survey out of the 175 
deposit taking SACCOs registered by SASRA to whom questionnaires were sent. In order to improve the response rate and considering that the survey was done during the COVID 19 pandemic, follow up calls were made to the respondents.

\section{Results and Discussion}

\subsection{Human Capital Focus}

The extent to which the leaders exhibited behaviour that indicated their human capital focus were assessed using four items. The items focused on considering feeling of employees before action, thoughtfulness, giving due considerations to the interests of followers, and whether encouraging employees to be the best they could be. The result of the analysis of the data collected on these measures of human capital focus is presented in Table 1.

\begin{tabular}{|c|c|c|c|c|c|}
\hline & $\mathbf{N}$ & Min & Max & M & SD \\
\hline My supervisor considers my feelings before acting & 133 & 1 & 5 & 3.53 & 1.056 \\
\hline $\begin{array}{l}\text { My supervisor behaves in a manner which is thoughtful of } \\
\text { my personal needs }\end{array}$ & 133 & 2 & 5 & 3.95 & 0.791 \\
\hline $\begin{array}{c}\text { My supervisor sees that my interests are given due } \\
\text { consideration }\end{array}$ & 133 & 1 & 5 & 3.77 & 1.178 \\
\hline My supervisor encourages me to be the best that I can be & 133 & 2 & 6 & 4.27 & 0.78 \\
\hline Human Capital Focus & 133 & 2.2 & 5 & 3.91 & 0.69 \\
\hline
\end{tabular}

Table 1: Human Capital Focus by Supervisors

There was moderately satisfactory human capital focus by the leaders in SACCOs in Kenya ( $M=3.91, S D=0.69$ ). The highest rated item was that 'my supervisor encourages me to be the best that I can be' $(\mathrm{M}=4.27, \mathrm{SD}=0.69)$. However, the least rated was 'My supervisor considers my feelings before acting' $(M=3.53, S D=1.06)$. This second result suggest that the supervisors need to consider feelings of their staff before acting because there appeared to be dissatisfaction with this aspect of human capital focus.

This finding is consistent with the findings by Abuzaid (2016, p. 328) that a 'strategic leader must be having the following skills: visioning, focusing, and implementing'. In particular, implementing speaks to execution of a strategy which involves maintaining focus on actions and activities of the organisation intended to ensure the realisation of the goals of the organisation.

\subsection{Organisational Effectiveness (Performance)}

In order to measure the performance of the SACCOs indicators of effectiveness which were anchored on a five point Likert scale were reported and the data analysed. Performance was be measured using effectiveness measures. The result in Table 2 is for the effectiveness of SACCOs where the respondents were asked to rate effectiveness measures over the 'in the last three years...' on three different measures (items) with regard to innovation of new products, improvement of coordination and adaptation to unanticipated changes.

\begin{tabular}{|c|c|c|c|c|c|}
\hline & $\mathbf{n}$ & Min & Max & M & SD \\
\hline $\begin{array}{c}\text { In the last there years ... } \\
\begin{array}{c}\text { My organisation has introduced innovations of new } \\
\text { products/services }\end{array}\end{array}$ & 133 & 1 & 5 & 3.93 & 1.07 \\
\hline $\begin{array}{c}\text { My organisation has improved its coordination of the } \\
\text { development efforts of different units }\end{array}$ & 133 & 1 & 5 & 3.92 & 1.01 \\
\hline My organisation is adapting quickly to unanticipated changes & 130 & 1 & 5 & 3.65 & 0.94 \\
\hline Organisational effectiveness & 133 & 1.7 & 5 & 3.80 & 0.79 \\
\hline Valid N (list wise) & 133 & & & & \\
\hline Table 2. Organisational Effectiveness
\end{tabular}

Table 2: Organisational Effectiveness

The SACCOs were only moderately effective because the composite mean score of all the item measure for performance (effectiveness) was 3.80 on a scale of 1 to 5 where $1=$ strongly disagree, $2=$ disagree, $3=$ somewhat agree, $4=$ agree and 5 =strongly disagree interpret the result and compare it with results from previous studies and cite.

These results suggest that leaders had a moderate human capital focus ( $M=3.91, \mathrm{SD}=.69)$, and that performance was also moderate $(\mathrm{M}=3.80, \mathrm{SD}=.79)$.

\subsection{Relationship between Human Capital Focus and Organisational Effectiveness}

The relationship between human capital focus and organisation performance was assessed using correlation analysis and the result is presented in Table 3 


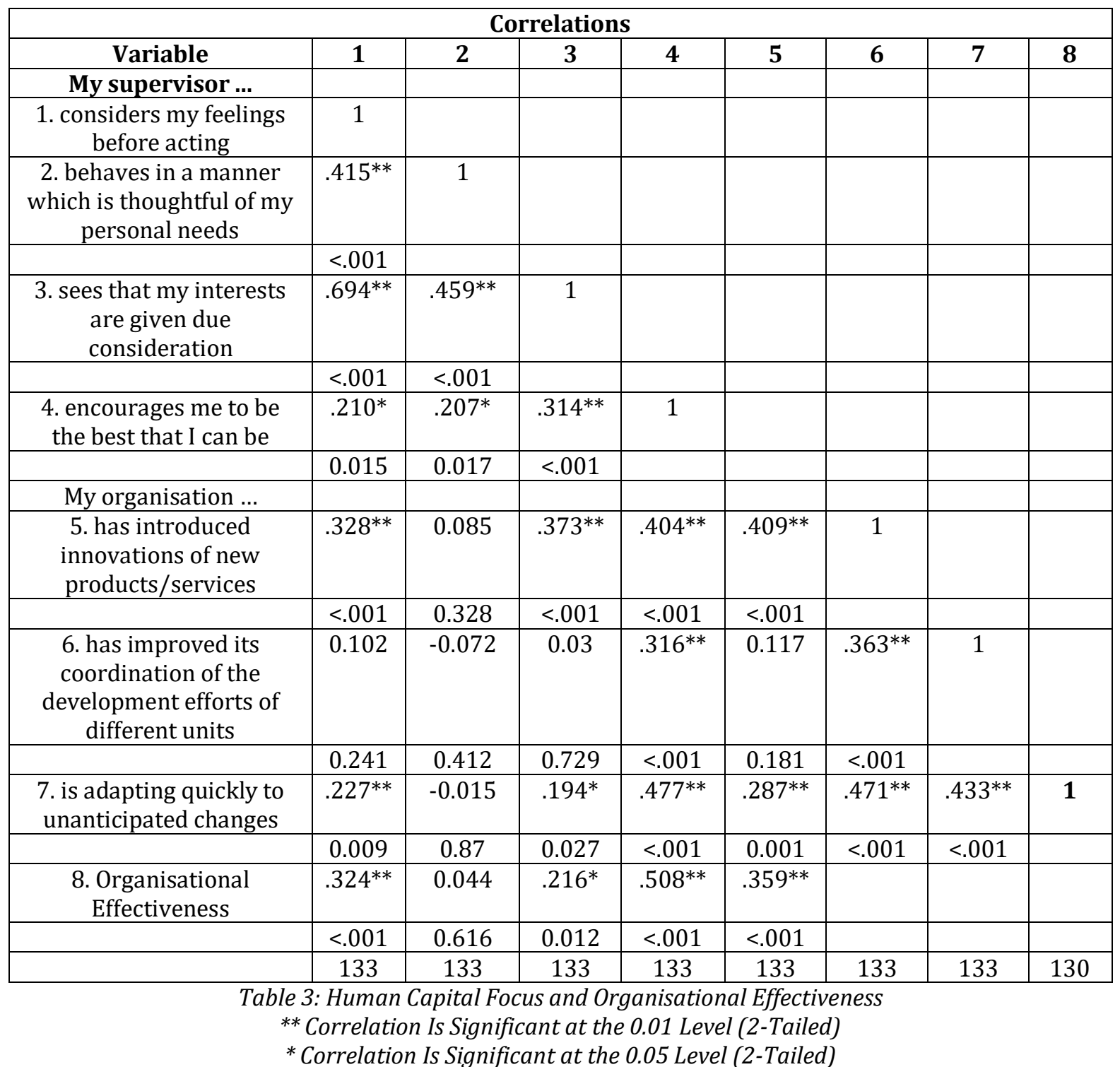

While consideration $(\mathrm{r}=.324, \mathrm{p}<.05)$, attention to employee interests $(\mathrm{r}=.216, \mathrm{p}<.05)$, and encouragement of employees to be the best they can be $(r=.508, p<.05)$ were significantly and positively related with organisational effectiveness (performance), managers' thoughtfulness of employee needs personal needs was not significantly related with performance $(r=.044, p=.616>.05)$. The strongest relationship was between encouragement of employees to be the best they can be and performance. Specifically, three leader human capital focus behaviors reported by followers: 'considers my feelings before acting' $(\mathrm{r}=.324, \mathrm{p}<.001)$, 'sees that my interests are given due consideration' $(\mathrm{r}=.216, \mathrm{p}=$ $0.012)$ ', and 'encourages me to be the best that I can be'( $\mathrm{r}=.508, \mathrm{p}<.001)$, were positively and significantly related with organizational effectiveness while 'behaves in a manner which is thoughtful of my personal needs' $(\mathrm{r}=.044, \mathrm{p}=.616>.05)$ was not significantly related with organisational effectiveness. In particular, inspiring the followers including encouraging them to be the best that they can be had the strongest relationship with performance. Overall, human capital focus was moderately correlated with organisational effectiveness $(r=.359, p<.001)$.

\subsection{Influence of Human Capital Focus on Performance}

Logit regression was used to examine the influence of human capital focus (consideration, thoughtfulness, attention to employee interests, and encouragement) on performance of SACCOs (measured using effectiveness indicators: innovation, coordination and adaptability); the result is presented in Table 4. 


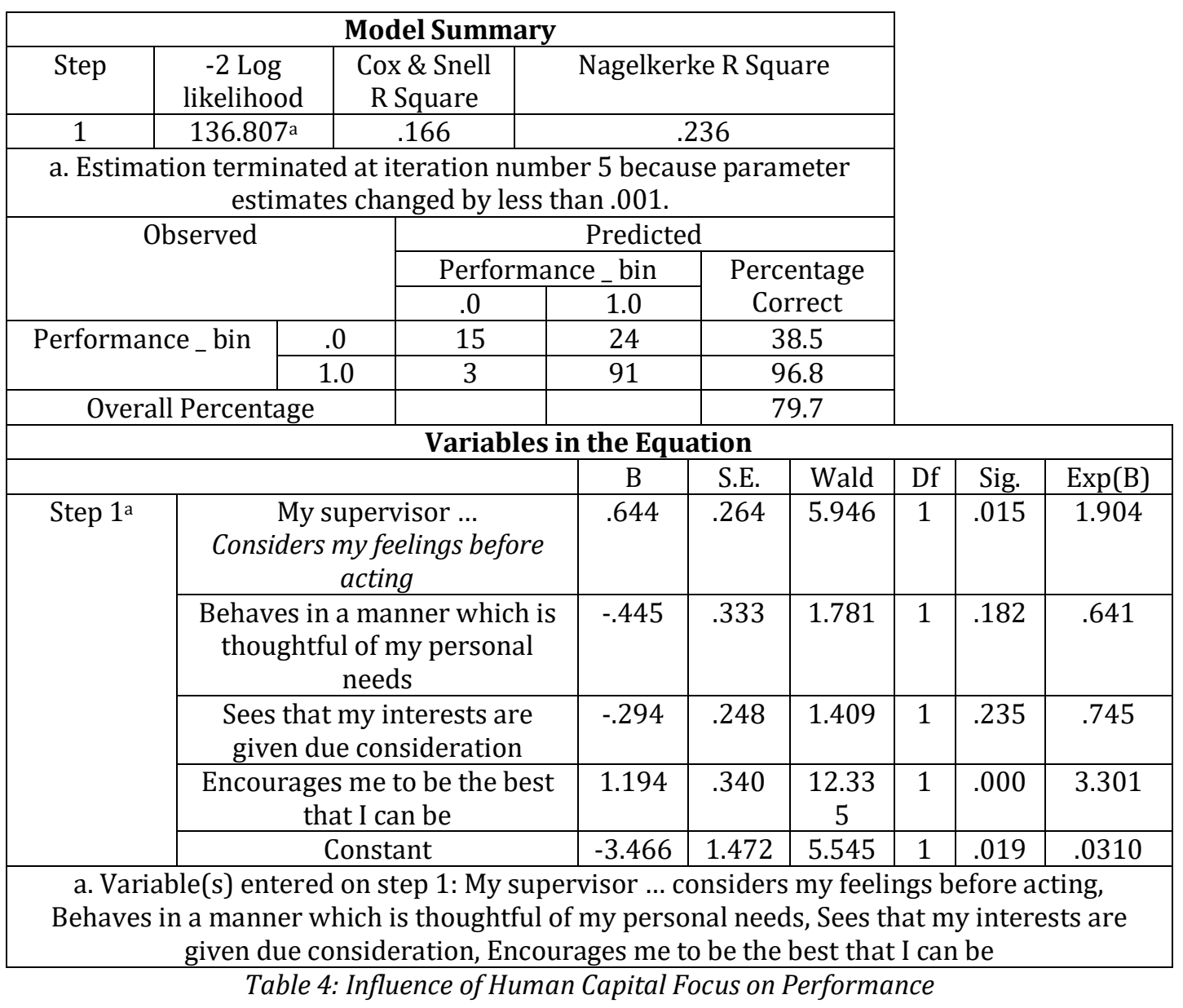

The logit results (Table 4) corroborated those of the correlation analysis with consideration and encouragement significantly influencing the probability of satisfactory performance; in other words, they significantly increased the odd for satisfactory performance of SACCOs. While 'encouragement' increased the odd more than threefold $(\exp (B)=3.301)$, consideration increased the odd for effectiveness (satisfactory performance) by about three times (exp (B) = 1.904). However, 'thoughtfulness' and 'attention of follower interests' did not significant influence the odds for organisational effectives (satisfactory performance) employee (thoughtfulness: Wald $=1.781, t=.182$, $\exp (\mathrm{B})=.641$; attention to follower interests: Wald $=1.409, t=.235$, exp $(B)=.745$ ). In addition, consideration of feelings and encouragement of followers significantly influenced probability of satisfactory performance by increasing the odds of satisfactory performance by about two times (exp (B) $=1.904)$ and more than threefold $(\exp (B)=3.301)$ respectively. These results, are corroborated by those by Ireland and Hitt (2005) who conceptualize strategic leadership as a set of unique capabilities of anticipating, envisioning, maintaining flexibility, thinking in a strategic way, and empowering employees to generate innovative ideas that lead to high performance. In this study, performance as measured by organisational effectiveness indicators (innovation, coordination and adaptability) was found to be significantly influenced by human capital focus which is one of the transformational leadership variables.

Consisted with these findings, the null hypotheses $\mathrm{H} 01$, and $\mathrm{H} 04$ were rejected, $\mathrm{H} 03$ partially rejected while $\mathrm{H} 02$ was accepted, thus: Consideration has a significant influence on organisational performance, Thoughtfulness has no significant relationship with organisational performance, Attention to follower interests has a significant relationship with organisational performance, and Encouragement has a significant influence organisational performance

These findings concur with those by Ogola and Senaji (2018) who on a sample from Kenya's parastatals tested and rejected (not supported) the null hypothesis that 'There is no significant relationship between 'individual consideration' and Organizational Performance' (p.18). In particular, individual consideration which a transformational leadership variables is concerned with the focus on the people in the organisation; in other words, it is the human capital focus enactment of the transformational leadership which was found to significantly influence performance.

\section{Conclusion and Applied Implications}

Human capital focus had significant influence on organisational performance. In particular, encouraging followers to be the best they can be had the greatest influence on performance followed by considering followers feelings before acting. However, 'thoughtfulness' and 'attention of follower interests' did not significantly influence the odds for organisational effectiveness (satisfactory performance).

These findings suggest that leaders should improve human capital focused behaviors in order to improve their performance because the practice of these behaviours and performance were only moderately satisfactory. Further, there is need to conduct further study to determine why leaders' thoughtfulness of followers' personal needs appeared not to significantly relate with performance. Further, since both thoughtfulness and attention to the interests of followers did not 
significantly influence the odds of effectiveness of the studied organisations, further investigation into the possible explanations is suggested. It is also suggested that since single item indicators were used for each of the human capital variables, more indicators could considered in order to compare the results. On the whole, this study extents literature on transformational leadership theory and human capital in the framework of strategy whose focus is on performance of organisations and what informs this performance, In this study, manager behaviours are seen as a resource which can be leveraged to encourage and inspire followers (or employees) to perform their best hence contributing to satisfactory performance.

\section{References}

i. Abuzaid, A. N. (2016). Testing the Impact of Strategic Leadership on Organizational Ambidexterity: A Field Study on the Jordanian Chemical Manufacturing Companies. International Journal of Business and Management, 11(5), 328 - 339. doi:10.5539/ijbm.v11n5p328

ii. Bass, B., \&Avolio, B (1994). Improving Organisational Effectiveness through Transformational Leadership. Thousand Oaks, CA: Sage Publications.

iii. Cronbach, L. (1951). Coefficient alpha and the internal structure of tests. Psychometrika. 16(3), $297-334$.

iv. Davies, B. J., \& Davies, B. (2014). Strategic Leadership. School Leadership \& Management, 24 (1), 29 - 38.

v. Easterby-Smith, M., Thorpe R., \& Lowe A. (1991). Management Research: An Introduction. London: Sage. Retrieved September 3, 2019 from http://ro.uwe.ac.uk/RenderPages/RenderLearningObject.aspx?Context=7\&Area=1\&Room=1\&Constellation=2\&L earningObject $=42$

vi. Ireland. R. D., \& Hitt, M. A. (2005). Achieving and maintaining strategic competitiveness in the 21st century: The role of strategic leadership. Academy of Management, 19 (4), 63 - 77. Reprinted from 1999 Vol 13 No.1

vii. Ogola, J. A. (2019). Influence of Transformational Leadership on Performance of State Corporations in Kenya. Unpublished PhD Thesis. Kenya Methodist University

viii. Ogolla, J., \& Senaji, T. A., (2018). Transformational Leadership and Organizational Performance in Kenya. Africa International Journal of Multidisciplinary Research (AIJMR), 3 (3), 12-21.

ix. Richard, O. C. (2009). Racial diversity, business strategy and firm performance: a resource-based view, Academy of Management Journal, 43(2), 164-177.

x. Yang, M. L. (2012). Transformational leadership and Taiwanese public relations practitioners" job satisfaction and organisational commitment. Social Behaviour and Personality: An International Journal, 40(1), 31-46.

xi. Zhu, Y., \& Akhtar, S. (2014). How transformational leadership influences follower-helping behaviour: the role of trust and prosocial motivation. Journal of Organisational Behaviour, 35, 373-392. 